\title{
Detection Rate and Clinical Pattern of Prostate Cancer in Kuwait: A Single-Center Experience
}

\author{
Arun Narayanaswamy $^{\mathrm{a}}$ Fawzi Abul $^{\mathrm{b}}$ T.C. Mathew ${ }^{\mathrm{c}}$ \\ a Department of Surgery, Urology Unit, Al Amiri Hospital, and b Department of Surgery, Faculty of Medicine, and \\ 'Faculty of Medicine and Faculty of Allied Health Sciences, Kuwait University, Jabriya, Kuwait
}

\section{Key Words}

Prostate cancer $\cdot$ Carcinoma, prostate $\cdot$ Detection rate

\begin{abstract}
Objective: To determine the detection rate and clinical pattern of prostate cancer in Kuwait. Subjects and Methods: One hundred and fifty-three males suspected of having prostate cancer based on elevation of prostate-specific antigen (PSA) of more than $4 \mathrm{ng} / \mathrm{ml}$ underwent transrectal-ultrasound (TRUS)-guided needle biopsy of the prostate between January 2003 and January 2008; these formed the study group. Analysis of prostate cancer was based on age, prostate volume, PSA level and on finding any abnormality based on a combination of the diagnostic tools. Results: A diagnosis of prostate cancer was histologically confirmed in $42(27.4 \%)$ patients. In those aged $<55,56-65,66-75$ and $>76$ years, the detection rates were $16.7,17.6,33.3$ and $40.7 \%$, respectively. In those with prostate volumes of $>71,51-70,31-$ 50 and $<30 \mathrm{~g}$, the detection rates were 18.2, 23.8, 30.8 and $42.9 \%$, respectively. When the PSA levels were divided into groups of 4-10, 10-20, 20-100 and >100 ng/ml, the cancer detection rate was $11.8,20.5,47.1$ and $83.3 \%$, respectively. When 1, 2 and 3 of the 3 diagnostic tools (digital rectal examination, PSA, TRUS) were abnormal, the detection rate was 15.6, 27.9 and $80 \%$, respectively. Conclusions: Our data showed that the prostate cancer rate differs according to the
\end{abstract}

region and that the rate was low in our center. Higher PSA and higher number of diagnostic tools with abnormal findings were associated with a higher incidence of prostate cancer.

Copyright $\odot 2010$ S. Karger AG, Basel

\section{Introduction}

Prostate cancer is a commonly detected cancer with a worldwide incidence of 25.3/100,000 and is one of the leading causes of cancer death in men. However, the incidence of prostate cancer varies widely according to the country and ethnicity [1]. Reported incidences of prostate cancer are: black American men, 222.9/100,000; white American men, 101/100,000; Japanese men, 9/100,000; Korean men, 7.12/100,000, and other Asian and Arab men, 3-9/100,000 [2-5].

Digital rectal examination (DRE), prostate-specific antigen (PSA) and transrectal ultrasonography (TRUS) are the main diagnostic tools of prostate cancer. The introduction of PSA in 1986 resulted in a dramatic worldwide increase in the reported incidence of prostate cancer. However, the serum PSA level is increased not only in patients with prostate cancer, but also in various nonmalignant conditions of the prostate, including inflammation. In general, only $25 \%$ of men undergoing prostate

\section{KARGER \\ Fax +4161306 1234 \\ E-Mail karger@karger.ch}

www.karger.com (c) 2010 S. Karger AG, Basel

1011-7571/11/0201-0034\$38.00/0

Accessible online at:

www.karger.com/mpp
Dr. Arun Narayanaswamy

Urology Unit - Ward 4

Al Amiri Hospital, PO Box 4077

Safat 13041 (Kuwait)

Tel. +965 6629 9701, Fax +965 2242 4135, E-Mail nandarun@gmail.com 
biopsy will receive a diagnosis of prostate cancer [6]. Researchers have proposed various practical PSA parameters, namely PSA velocity, PSA density and percentage free PSA, to improve the performance of PSA. Another recent strategy has been to construct simple nomograms based on readily available parameters such as the above PSA parameters, age, prostate volume and TRUS findings. This would allow patients to be informed of their actual probability of having prostate cancer and thus aid both the physician and patient in deciding whether or not to pursue an initial and, even more critically, a repeated prostate biopsy.

We undertook this study to determine the detection rate of prostate cancer in patients undergoing prostate biopsy in Kuwait. We also determined the detection rate based on age, prostate volume, PSA level and number of diagnostic tools with abnormal findings to determine the feasibility of developing nomograms for this region.

\section{Subjects and Methods}

A total of 153 men who underwent TRUS-guided needle biopsy of the prostate between January 2003 and January 2008 formed the study group. Patients undergoing repeat biopsies were excluded from the study. All patients were suspected to have prostate cancer based on an elevated PSA (more than $4.0 \mathrm{ng} / \mathrm{ml}$ ). A careful DRE was done in all patients; suspicious findings included induration, asymmetry or irregularity.

TRUS was done using a Voluson (General Electric Vivid 3) ultrasound machine equipped with a transrectal 5- to $8-\mathrm{MHz}$ curvilinear transducer. The transducer design includes 360-degree radial scanners paired with an end viewing transducer for multiplanar imaging in semicoronal, sagittal and axial projections. Presence of any sonographic suspicious lesions (hypoechoic areas in the posterior peripheral zone) was noted. A mid-transverse view of the prostate was obtained, and the volume was determined using the software program in the ultrasound machine called 'Vocal'. Volume was determined assuming the prostate to be elliptical in shape and using the formula (width $\times$ length $\times$ height $\times 0.523)$. Lesion-targeted and/or random biopsies were performed using 4-dimensional TRUS guidance with an automatic core biopsy device (Bard Magnum biopsy instrument) and an 18-gauge core tissue biopsy needle (Bard Magnum). The biopsy specimens were put in separate containers with $10 \%$ formaldehyde and were evaluated by several experienced pathologists.

Records of all the patients were reviewed and the following variables were studied: age, presentation, DRE findings, volume of the prostate gland, PSA levels, TRUS characteristics and histopathological findings. The overall prostate cancer detection rate was determined. The patients were grouped according to: age, $<55$, $56-65,66-75$ and $>76$ years; volume of the prostate gland, $<30$, $31-50,51-70$ and $>71$ g; PSA level, 4-10, 10-20, 20-100 and $>100$ $\mathrm{ng} / \mathrm{ml}$; and the number of diagnostic tools with abnormal findings, 1,2 and 3 . The detection rate in all the subgroups was noted.

Detection Rate and Clinical Pattern of

Prostate Cancer in Kuwait

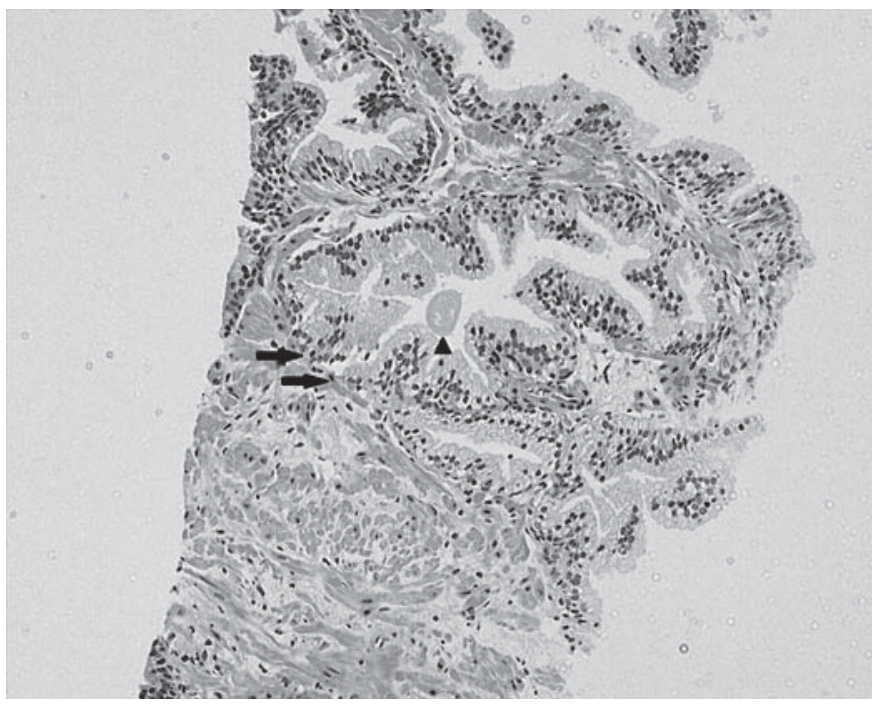

Fig. 1. Hematoxylin and eosin stain showing an area of fibromuscular glandular hyperplasia (arrows) with corpus amylaceum (arrowhead) in the glandular space. $\times 300$.

Data were analyzed using the computer statistical program SPSS (version 15). To determine the differences in the various parameters, $t$ test and analysis of variance were used when appropriate. In addition, a post-hoc test (Scheffé) was performed as pairwise comparison between different groups. Statistical significance was at 0.05 .

\section{Results}

The mean age of the study population was 65 years. Presentation was obstructive urinary symptoms in 122 (79.8\%) patients and retention of urine in 31 (20.2\%). Since we do not have an active screening program, there were no asymptomatic patients. The average number of biopsy cores was 6.83 (range 6-12). Of the 153 patients, a diagnosis of prostate cancer (fig. 1) was histologically confirmed in $42(27.4 \%)$ patients. In the remaining $111(72.6 \%)$ patients, the diagnosis was benign prostatic hyperplasia (fig. 2) and was associated with prostatitis in 46 patients. The characteristics of the study group are shown in table 1 . Men with prostate cancer ( $\geq 70$ years) were older than men with benign disease ( $\geq 63$ years) and also had a higher total PSA level (153 vs. $15.17 \mathrm{ng} / \mathrm{ml}$ ). The average prostate volume was lower in the men with prostate cancer. There were no significant differences in the nature of presentation.

The observed prostate cancer rates for each variable are given in the following tables: age in table 2, PSA level in table 3 , prostate volume in table 4 , and number of tools 


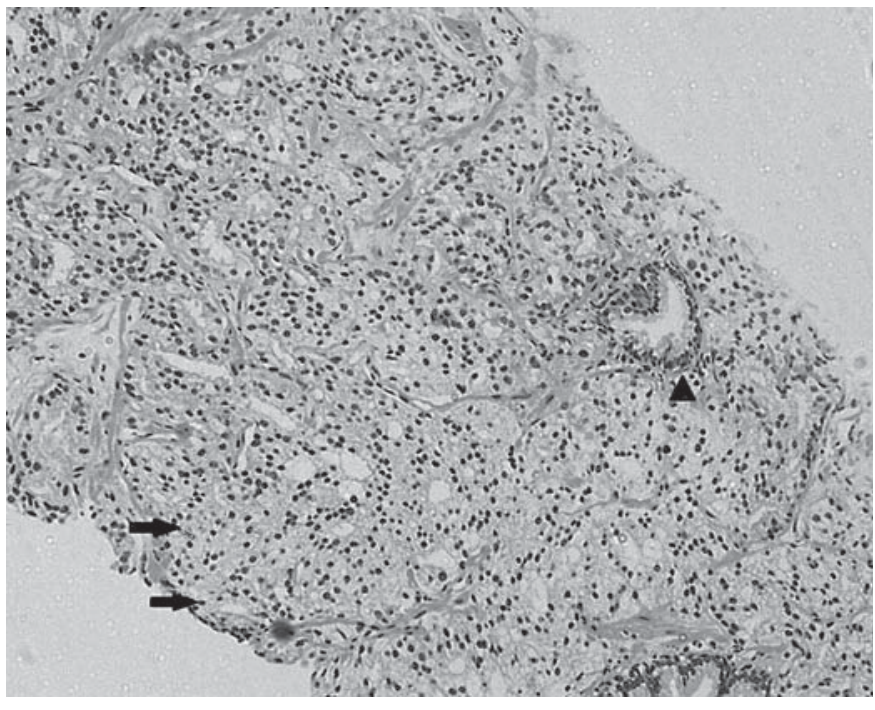

Fig. 2. Hematoxylin and eosin stain showing an area of adenocarcinoma Gleason stage 3 (arrows) and some benign glands (arrowhead). $\times 200$.

with abnormal findings in table 5. The detection rate increased with increasing PSA level (from 11.8 to $83.3 \%$ ), age (from 16.7 to $40.7 \%$ ) and decreasing prostate volume (from 18.2 to $42.9 \%$ ). When only 1 of the 3 diagnostic tools (DRE, PSA, TRUS) was abnormal, the detection was $15.6 \%$. The detection rate increased to $27.9 \%$ when 2 of the tools were abnormal and further increased to $80 \%$ when all 3 were abnormal (table 5). The higher detection rate with increasing PSA level and higher number of diagnostic tools with positive results was statistically significant $(\mathrm{p}<0.01)$. The higher detection rate with increasing age and increasing prostate volume was not statistically significant $(\mathrm{p}<0.01)$.

\section{Discussion}

With the widespread use of PSA, the incidence of prostate cancer is increasing worldwide. However compared to the Western countries, the incidence in Arab men is lower [1-5]. In this study, the overall detection rate of prostate cancer in patients with elevated PSA levels was 27.4\%. The detection rate in patients with PSA levels between 4 and $10 \mathrm{ng} / \mathrm{ml}$ was $11.8 \%$, which is slightly lower than the $15.8 \%$ rate reported in Japanese and Korean men $[3,7]$, and much lower than the $25-35 \%$ rate reported in American men [8-11]. In patients with PSA levels more than $10 \mathrm{ng} / \mathrm{ml}$ also, our detection rate of $40 \%$ is lower
Table 1. Patient characteristics

\begin{tabular}{lcc}
\hline Characteristic & Malignant & Benign \\
\hline $\begin{array}{l}\text { Number of patients } \\
\text { Age*, years }\end{array}$ & 42 & 111 \\
$\quad$ Mean & & \\
Range & $70 \pm 9.2$ & $63 \pm 8.4$ \\
PSA $^{*}$ ng/ml & $49-87$ & $45-81$ \\
$\quad$ Mean & & \\
Range & $153.2 \pm 278.2$ & $15.17 \pm 21$ \\
Prostatic volume*, g & $4.1-1,600$ & $4.1-146$ \\
$\quad$ Mean & $48.73 \pm 19.6$ & $65.86 \pm 34.2$ \\
Range & $20-90$ & $16-200$ \\
\hline \multirow{2}{*}{ p $<0.05}$. & & \\
\hline
\end{tabular}

Table 2. Relationship between age and detection rate

\begin{tabular}{lllll}
\hline Group & $\begin{array}{l}\text { Age range, } \\
\text { years }\end{array}$ & $\begin{array}{l}\text { Number } \\
\text { of patients }\end{array}$ & $\begin{array}{l}\text { Number } \\
\text { malignant }\end{array}$ & $\begin{array}{l}\text { Detection } \\
\text { rate, \% }\end{array}$ \\
\hline 1 & $45-54$ & 18 & 3 & 16.7 \\
2 & $55-64$ & 51 & 9 & 17.6 \\
3 & $65-74$ & 57 & 19 & 33.3 \\
4 & $75-87$ & 27 & 11 & 40.7 \\
\hline
\end{tabular}

$\mathrm{p}>0.05$ (no significant association).

Table 3. Relation between PSA and detection rate

\begin{tabular}{lllll}
\hline Group & $\begin{array}{l}\text { PSA level, } \\
\text { ng/ml }\end{array}$ & $\begin{array}{l}\text { Number } \\
\text { of patients }\end{array}$ & $\begin{array}{l}\text { Number } \\
\text { malignant }\end{array}$ & $\begin{array}{l}\text { Detection } \\
\text { rate, \% }\end{array}$ \\
\hline 1 & $4-10$ & 68 & 8 & 11.8 \\
2 & $1-20$ & 39 & 8 & 20.5 \\
3 & $2-100$ & 34 & 16 & 47.1 \\
4 & $>100$ & 12 & 10 & 83.3 \\
\hline
\end{tabular}

$\mathrm{p}<0.01$ (significant association).

than the 59.5\% rate reported in Korean and Japanese men, and the $67 \%$ rate reported in American men $[3,11]$. The reason for a lower incidence of prostate cancer in $\mathrm{Ku}$ waiti men has been suggested to be due to low circulating androgens and their adrenal precursors when compared to Caucasians [12]. Therefore it seems that prostate can- 
Table 4. Relation between prostate volume and detection rate

\begin{tabular}{lllll}
\hline Group & $\begin{array}{l}\text { Volume, } \\
\mathrm{g}\end{array}$ & $\begin{array}{l}\text { Number } \\
\text { of patients }\end{array}$ & $\begin{array}{l}\text { Number } \\
\text { malignant }\end{array}$ & $\begin{array}{l}\text { Detection } \\
\text { rate, \% }\end{array}$ \\
\hline 1 & $16-30$ & 28 & 12 & 42.9 \\
2 & $31-50$ & 39 & 12 & 30.8 \\
3 & $51-70$ & 42 & 10 & 23.8 \\
4 & $71-200$ & 44 & 8 & 18.2 \\
\hline
\end{tabular}

p $>0.05$ (no significant association).

Table 5. Relation between number of abnormalities (DRE, PSA and TRUS) and detection rate

\begin{tabular}{lllll}
\hline Group & $\begin{array}{l}\text { Number of } \\
\text { abnormalities }\end{array}$ & $\begin{array}{l}\text { Number } \\
\text { of patients }\end{array}$ & $\begin{array}{l}\text { Number } \\
\text { malignant }\end{array}$ & $\begin{array}{l}\text { Detection } \\
\text { rate, \% }\end{array}$ \\
\hline 1 & 1 & 90 & 14 & 15.6 \\
2 & 2 & 43 & 12 & 27.9 \\
3 & 3 & 20 & 16 & 80.0 \\
\hline
\end{tabular}

$\mathrm{p}<0.01$ (significant association)

cer differs epidemiologically and biologically between different ethnic groups.

Prostate cancer screening with PSA is considered a sensitive way to identify men at risk of prostate cancer, but it cannot distinguish those who have an elevated PSA level but who are not at risk. Studies have shown that on average PSA values $>4 \mathrm{ng} / \mathrm{ml}$ can occur in $27 \%$ of men with benign disease, such as benign prostatic hyperplasia, and this lack of specificity results in the performance of many unnecessary biopsies $[9,13,14]$. In order to reduce this, several practical PSA parameters such as agespecific reference ranges, PSA density, PSA velocity, free/ total PSA and p53 antibody have been suggested to improve the specificity $[15,16]$. However, it seems that PSA provides little predictive value for an individual patient in deciding whether or not to pursue an initial and, even more critically, a repeated biopsy. In order to address this issue, efforts have been made to develop predictive models for the risk of prostate cancer using clinical, laboratory and ultrasound parameters. Garzotto et al. [17] developed a nomogram to predict the presence of prostate cancer using age, PSA density, DRE and TRUS findings in patients with intermediate PSA levels. Carlson et al. [8] developed an algorithm combining age, total PSA and percentage of free PSA. Other groups also showed that nomograms using age, prostate volume, PSA and DRE may be used successfully for predicting the risk of prostate cancer [18-20]. Using these nomograms, the decision to proceed with, or defer, a prostate biopsy can be based on the actual likelihood of having prostate cancer discovered rather than a single PSA-based cutoff point. As was seen earlier, prostate cancer differs epidemiologically and biologically between different ethnic groups. It follows that nomograms developed in Western countries may not be directly applicable to our population in whom the incidence of prostate cancer is lower.

An analysis of the clinical parameters of patient age, volume of prostate, PSA level and number of diagnostic tools with abnormal findings showed that increasing age, smaller prostate volume and higher PSA were associated with a significantly higher incidence of prostate cancer (tables 2-5). Also, the higher the number of diagnostic tools (PSA, DRE, TRUS) with abnormal results, the higher was the incidence of prostate cancer. Statistical significance was established for PSA and number of diagnostic tools with abnormal results $(\mathrm{p}<0.01)$. Though statistical significance was not demonstrated for the higher detection rate of prostate cancer with increasing age $(\mathrm{p}<0.01)$ and decreasing prostate volume, there was a clear increasing trend (tables 2 and 4). With higher numbers of patients it is likely that statistical significance may be demonstrated for these parameters too. Similar observations were reported by Uzzo et al. [21], who found a 38\% incidence of prostate cancer in patients with prostate volume $<50 \mathrm{~g}$ and a $23 \%$ incidence when the prostate volume was $>50 \mathrm{~g}$. This lower incidence may be due to sampling error when performing biopsy on larger glands. Prostatitis is more common in younger men and may be the cause of the frequently observed rise in PSA level in benign groups as previously reported $[22,23]$, and this may be the factor responsible for the lower detection rate in younger age groups in our study (table 2). In our study, a higher proportion of men with prostate cancer were $>65$ years of age (30/42; 71.4\%), had a prostate volume $<50 \mathrm{~g}$ ( 24 out of 42 patients) and showed abnormality in 2 or more of the diagnostic tools (28 out of 42 patients). Therefore, it appears that higher PSA and more abnormal diagnostic tools are associated with a higher risk of prostate cancer. However, we could not test previously described nomograms on our patients due to lack of adequate follow-up. Hence we recommend multicenter prospective studies, in order to test these nomograms.

Shortcomings of this study were that the number of biopsy cores was not standardized and many biopsies in 
the initial part of the study were extant as they were performed before we adopted a standard 12-core biopsy. Also the biopsies were not performed by one investigator. This is a problem of the retrospective nature of a study such as ours. The recent recommendation of increasing the number of biopsy cores and/or transperineal approach has generated a greater prostate cancer detection rate [24]. Whether this will lead to detection of insignificant cancers is being debated [25]. These aspects will have to be considered in future studies.

\section{Conclusion}

Our data showed that the prostate cancer rate differs according to the region and the rate was low in our center. A combination of age, DRE, prostate volume, PSA level and TRUS findings better defined the probability of a positive biopsy than any one factor alone. Our observations suggest that higher PSA level and higher number of diagnostic tools with abnormal findings were associated with a higher incidence of prostate cancer.

\section{References}

1 Parkin DM, Whelan SL, Ferlay J: Cancer Incidence in Five Continents, ed 7. Lyon, International Agency for Research on Cancer, 1997, pp 1-35.

72 Nelen V: Epidemiology of prostate cancer. Recent Results Cancer Res 2007;175:1-8.

-3 Yang WJ, Lee DH, Chung BH, Cho JS, Choi YD, Kim SJ, Cho IR, Kim HS, Kim CI, Hong SJ: Detection rate of prostate cancer on biopsy according to serum prostate specific antigen in Korean men: a multicenter study. Urology 2006;67:333-336.

4 Memon A, Al Muhanna AN: Annual cancer incidence in Kuwaitis 1992-1993; in Parkin DM, Whelan SL, Ferlay J, Raymond L, Young $J$ (eds): Cancer Incidence in Five Continents. Lyon, IARC Scientific Publications, 1997, vol VII, No 143, pp 410-417.

5 Hanash KA, Al-Othaimeen A, Kattan S, Lindstedt E, Al-Zahrani H, Merdad T, Peracha A, Kardar AH, Aslam M, Al-Akkad A: Prostatic carcinoma: a nutritional disease? Conflicting data from the Kingdom of Saudi Arabia. J Urol 2000;164:1570-1572.

-6 Arcangali CG, Ornstein DK, Keetch DW, Andriole GL: Prostate specific antigen as a screening test for prostate cancer. Urol Clin North Am 1997;24:299-305.

-7 Egawa S, Matsumoto K, Yoshida K, Iwamura M, Kuwao S, Koshiba K: Results of transrectal ultrasound-guided biopsies and clinical significance of Japanese prostate cancer. Jpn J Clin Oncol 1998;28:666-672.

-8 Carlson GD, Calvanese CB, Partin AW: An algorithm combining age, total prostate specific antigen (PSA), and percent free PSA to predict prostate cancer: results on 4,298 cases. Urology 1998;52:455-461.

9 Cooner WH, Mosley BR, Rutherford CL Jr, Beard JH, Pond HS, Terry WJ, Igel TC, Kidd DD: Prostate cancer detection in a clinical oncology practice by ultrasonography, digital rectal examination and prostate specific antigen. J Urol 1990;143:1146-1154.
10 Catalona WJ, Richie JP, Ahmann FR, Hudson MA, Scardino PT, Flanigan RC, de Kernion JB, Ratliff TL, Kavoussi LR, Dalkin BL: Comparison of digital rectal examination and prostate specific antigen in the early detection of prostate cancer: results of a multicentre clinical trial of 6,630 men. J Urol 1994;151:1283-1290.

11 Gretzer MB, Partin AW: PSA levels and the detection rate of prostate cancer on biopsy. Eur Urol 2002;1(suppl):21-27.

-12 Kehinde EO, Akanji AO, Al-Hunayan A, Memon A, Luqmani Y, Al-Awadi KA, Varghese R, Bashir AA, Daar AS: Do differences in age specific androgenic steroid hormone levels account for differing prostate cancer rates between Arabs and Caucasians? Int J Urol 2006;13:354-361.

13 Partin AW, Carter HB, Chan DW, Epstein JI, Oesterling JE, Rock RC, Weber JP, Walsh PC: Prostate specific antigen in the staging of localized prostate cancer: influence of tumor differentiation, tumor volume and benign hyperplasia. J Urol 1990;143:747-752.

14 Hudson MA, Bahnson RR, Catalona WJ: Clinical use of prostate specific antigen in patients with prostate cancer. J Urol 1989; 142:1011-1017.

15 Catalona WJ, Partin AW, Slawin KM, Brawer MK, Flanigan RC, Patel A, Richie JP, de Kernion JB, Walsh PC, Scardino PT, Lange $\mathrm{PH}$, Subong EN, Parson RE, Gasior GH, Loveland KG, Southwick PC: Use of the percentage of free prostate-specific antigen to enhance differentiation of prostate cancer from benign prostate disease: a prospective multicentre clinical trial. JAMA 1998;279: 1542-1547.

16 Suzuki H, Akakura K, Igarashi T, Ueda T, Ito H, Watanabe M, Nomura F, Ochiai T, Shimada $\mathrm{H}$ : Clinical usefulness of serum antip53 antibodies for prostate cancer detection: a comparative study with PSA parameters. J Urol 2004;171:182-186.
17 Garzotto M, Hudson RG, Peters L, Hsieh YC, Barrera E, Mori M, Beer TM, Klein T: Predictive modeling for the presence of prostate carcinoma using clinical, laboratory and ultrasound parameters in patients with prostate specific antigen $<10 \mathrm{ng} / \mathrm{ml}$. Cancer 2003; 98:1417-1422.

18 Potter SR, Horniger W, Tinzl M, Bartsch G, Partin AW: Age, prostate specific antigen, and digital rectal examination as determinants of the probability of having prostate cancer. Urology 2001;57:1100-1104.

19 Suzuki H, Komiya A, Kamiya N: Development of a nomogram to predict probability of positive initial prostate biopsy among Japanese patients. Urology 2006;67:131-136.

20 Nam RK, Toi A, Klotz LH, Trachtenberg J, Jewett MA, Appu S, Loblaw DA, Sugar L, Narod SA, Kattan MW: Assessing individual risk for prostate cancer. J Clin Oncol 2007;25: 3582-3588.

21 Uzzo RG, Wei JT, Waldbaum RS, Perlmutter AP, Byrne JC, Vaughan ED Jr: The influence of prostate size on cancer detection. Urology 1995;46:831-836.

22 Orozco R, Kunnel B, O’Dowd GJ, Stamey TA: Positive prostate biopsy rate consistently increases with age at the same prostate-specific antigen level in patient with normal digital rectal examination. Urology 1998;51: 531-533.

23 Kehinde EO, Sheikh M, Mojimoniyi OA, Francis I, Anim JT, Nkansa-Dwamena D, AlAwadi KA: High serum prostate specific antigen levels in the absence of prostate cancer in Middle-Eastern men: the clinician's dilemma. BJU Int 2003;91:618-622.

24 Scattoni V, Zlotta A, Montironi R, Schulman C, Rigatti P, Montorsi F: Extended and saturation prostatic biopsy in the diagnosis and characterisation of prostate cancer: a critical analysis of the literature. Eur Urol 2007;52: 1309-1322.

-25 Samaratunga H, Yaxley J, Kerr K, McClymont K, Duffy D: Significance of minute focus of adenocarcinoma on prostate needle biopsy. Urology 2007;70:299-302. 